\title{
OPTIMAL INSURANCE ARRANGEMENTS
}

\section{KARL BORCH}

I. In a recent paper on the theory of demand for insurance Arrow $[I]$ has proved that the optimal policy for an insurance buyer is one which gives complete coverage, beyond a fixed deductible. The result is proved under very general assumptions, but its content can be illustrated by the following simple example.

Assume that a person is exposed to a risk which can cause him a loss $x$, represented by a stochastic variable with the distribution $F(x)$. Assume further that he by paying the premium $P(y)$ can obtain an insurance contract which will guarantee him a compensation $y(x)$, if his loss amounts to $x$. The problem of our person is to find the optimal insurance contract, i.e. the optimal function $y(x)$, when the price is given by the functional $P(y)$.

2. In order to give an operational formulation to the problem we have outlined, we shall assume that the person's attitude to risk can be represented by a Bernoulli utility function $u(x)$, and we shall write $S$ for his "initial wealth". His problem will then be to maximize

$$
\int_{0}^{\infty} u(S-P(y)-x+y(x)) d F(x),
$$

when the functional $P(y)$ is given, and $y(x) \varepsilon Y$. The set $Y$ can be interpreted as the set of insurance policies available in the market. It is natural to assume that $0 \leq y(x) \leq x$, but beyond this there is no need for assuming additional restrictions on the set $Y$.

Arrow makes the assumption that

$$
P(y)=(\mathrm{x}+\lambda) \int_{0}^{\infty} y(x) d F(x)
$$

i.e. that the premium is proportional to the net premium, with a loading $\lambda$. With this assumption he proves that the optimal policy is of the form

$$
\begin{array}{ll}
y(x)=0 & \text { for } x<M \\
y(x)=x-M & \text { for } x \geq M
\end{array}
$$


The problem of determining the optimal insurance contract is then reduced to finding the optimal deductible $M$, i.e. to the problem:

$$
\max _{0 \leq M}\left\{\int_{0}^{M} u(S-P-x) d F(x)+u(S-P-M) \int_{M}^{\infty} d F(x)\right\}
$$

subject to

$$
P=(\mathrm{I}+\lambda) \int_{M}^{\infty}(x-M) d F(x)
$$

3. Writing

$$
U=\int_{0}^{M} u(S-P-x) d F(x)+u(S-P-M) \int_{M}^{\infty} d F(x)
$$

we obtain

$$
\begin{aligned}
\frac{d U}{d M}=-\frac{d P}{d M} \int_{0}^{M} u^{\prime}(S- & P-x) d F(x)- \\
& \quad\left(\mathrm{I}+\frac{d P}{d M}\right) u^{\prime}(S-P-M)\{\mathrm{I}-F(M)\}
\end{aligned}
$$

From (2) it follows that

$$
\frac{d P}{d M}=-(\mathrm{I}+\lambda)\{\mathrm{I}-F(M)\} .
$$

Hence we obtain the following equation for the determination of the optimal deductible $M$ :

$(\mathrm{I}+\lambda) \int_{0}^{M} u^{\prime}(S-P-x) d F(x)=\{(\mathrm{I}+\lambda) F(M)-\lambda\} u^{\prime}(S-P-M)$.

From this equation we can prove that the optimal $M$ will increase with the loading $\lambda$, provided that $u^{\prime \prime}(x)<0$. This result is a special case of Arrow's Theorem 6, and it means that as insurance becomes more expensive, the consumer buys less of it.

4. It should be easy to recognize Arrow's results as generalizations of results familiar from the theory of reinsurance. Several authors have shown, i.a. in [2], [6] and [7], that a stop loss treaty is the optimal reinsurance arrangement, from the ceding company's point 
of view. These authors have proved their result under more restrictive assumptions than Arrow, but it is clearly equivalent to his. When a private person buys full insurance with a deductible, he does in reality conclude a stop loss contract.

A reinsurance treaty is generally a contract negociated on equal terms between two insurance companies. It is not usual that the reinsurer states his price-system, for instance in the form of condition (I), and then lets the ceding company select the function $y(x)$ which it considers as most advantageous. This means that it makes little sense to study arrangements which are optimal for only one of the parties to the negociations. Both parties have to be considered and this has been pointed out in several papers, i.a. in [4] and [8].

5. The considerations above suggest that the situation could be formulated as a problem in game theory. Assume that the claim distribution $F(x)$ of the ceding company is given. The game would then be played in two moves:

(i) The reinsurer selects a mapping $P(y)$ from the set of functions $y(x)$, such that $\{y(x) \mid 0 \leq y(x) \leq x\}$ to the real line. $P(y)$ will be the premium he demands for a contract obliging him to pay an amount $y(x)$, if claims against the ceding company amount to $x$.

(ii) The ceding company selects a function $y(x)$.

This problem may have some mathematical interest, but its relevance to reinsurance in real life seems doubtful. There is little evidence that insurance companies behave in this way during reinsurance negociations. The game-theoretical formulation outlined may, however, be appropriate in direct insurance.

6. Arrow's results indicate that much of the insurance currently sold may be sub-optimal from the consumer's point of view. This would, for instance, apply to all kinds of liability policies, which place an upper limit on the company's obligations. Such policies may give the insured inadequate protection if extremely unlikely catastrophic events should occur. In most cases there is no reason why the company should not provide full cover, but it seems natural that the company should be unwilling to provide such catastrophe cover against an infinitesimal net premium with a 
"normal" proportional loading. Hence it appaers that assumption (I) is the critical element behind Arrow's results.

It is easy to construct examples which show that an insurance company cannot in general operate with premium rates as assumed by (I).

We can, for instance, assume that there are some fixed costs $c$ associated with issuing and handling the insurance contract. With a deductible $M$, the net premium is

$$
\bar{P}(M)=\int_{M}^{\infty}(x-M) d F(x)
$$

The minimum premium which the company can quote to customers will then be

$$
P(M)=\bar{P}(M)+c=\left\{\mathrm{I}+\frac{c}{\bar{P}(M)}\right\} \bar{P}(M)
$$

Hence the loading will be

$$
\lambda=\frac{c}{\bar{P}(M)}
$$

which must increase with the deductible $M$.

7. We can reach a similar result by a simple risk theory argument. Assume that

$$
P(M)=(\mathrm{I}+\lambda) \overline{P(} M)
$$

so that the company's expected profit from the contract is $\lambda \overline{P(} M)$. The variance of the profit is

$$
V(M)=\int_{M}^{\infty}(x-M)^{2} d F(x)-(\bar{P}(M))^{2}
$$

It is natural to require that

$$
\lambda^{2}(\bar{P}(M))^{2}=k^{2} V(M)
$$

This condition can be written

$$
\lambda^{2}=k^{2}\left\{\left[\int_{M}^{\infty}(x-M) d F(x)\right]^{-2} \int_{M}^{\infty}(x-M)^{2} d F(x)-\mathrm{I}\right\}
$$

With L'Hospital's rule it is easy to show that the first term on the right-hand side goes to infinity with $M$. 
The condition (3) can be justified by an appeal to the Hattendorff rule in classical risk theory. Assume that the company holds a large number of insurance contracts, so that the claim distribution of its portfolio is approximately normal. The probability of negative profit (or of ruin) may then be considered as satisfactorily low if the loading is at least equal to $k$ times the standard deviation. If now one person wants a larger deductible in order to reduce his premium, the company must quote him a premium, so that (3) remains satisfied.

8. Our two simple examples open some unpleasant perspectives. Assume that an insurance company for some reason must increase the loading on its premiums. If the company uses formula (I), i.e. retains a proportional loading, this will induce the customers to take higher deductibles. This will again force the company to increase the loading - to cover costs, or to satisfy solvency requirements. It is a sobering thought to ask if a process of this kind can occur in real life, and if the process, once started, will ever stop

9. In the discussion above we have in a sense taken existing institutions and current insurance practice as given. It may be useful for a time to forget about these, and study general arrangements for risk sharing, which can be considered optimal. We can then ask ourself if there are institutional or other aspects which make it impossible to make such arrangements in practice.

We shall consider a group of $n$ persons, and assume:

(i) Person $i$ is exposed to a risk which can cause him a loss, represented by a stochastic variable $x_{i}$.

(ii) The attitude to risk of person $i$ can be represented by a utility function $u_{i}(x)$.

The most general insurance arrangement these persons can make will be defined by a set of functions $y_{i}\left(x_{1} \ldots x_{n}\right)(i=\mathrm{I}, 2, \ldots n)$ stating the loss which will be carried by person $i$ if all losses are given by the vector $\left\{x_{1} \ldots x_{n}\right\}$. An arrangement defined by a set of $y$-functions which satisfies the following conditions, will be Pareto optimal:

$$
k_{i} u_{i}^{\prime}\left(-y_{i}(x)\right)=k_{j} u_{j}^{\prime}\left(-y_{j}(x)\right)
$$


Here $k_{1} \ldots k_{n}$ are arbitrary positive constants,

$$
x=\sum_{i=1}^{n} x_{i} \text { and } \sum_{i=1}^{n} y_{i}(x)=x .
$$

This result was first proved in [3]. More stream-lined proofs have been given in a number of later publications, i.a. in [5].

Io. In real life we do not often find insurance arrangements which meet the conditions of Pareto optimality, but there are cases in which these conditions may be approximately satisfied.

(i) The mutual fire-insurance schemes which still can be found in some rural communities, may come close to satisfying (4).

(ii) Some large liability risks in business are currently insured by mutual arrangements. Shipowners have formed their P \& I Clubs, and off shore oil operators have devised their own insurance schemes, which may approximately satisfy (4).

It is, however, clear that such insurance arrangements made by relatively small groups can be improved by cooperation with other groups.

II. Arrow's results demonstrate that the normal risk-averse person wants an insurance which places an upper limit on the loss he can suffer, i.e. he wants an arrangement which satisfies a condition of the form

$$
P_{i} \geq y_{i}\left(x_{1} \ldots x_{n}\right)
$$

With strict equality this becomes a conventional insurance contract with premium $P_{i}$. Condition (5) may satisfy (4) for some $i$, provided that there are other persons which are willing to carry unlimited liability. This argument indicates that an institution as Lloyds of London is essential to bring about an optimal insurance arrangement.

In practice most insurance is sold by companies with limited liability. This means that condition (5) cannot be satisfied in an absolute manner. There will always be a non-zero probability that the insured may suffer a loss beyond the premium he has paid. The task of the government supervision is to see that this probably is sufficiently low, preferably infinitesimal. This is usually achieved 
by requiring that the company must hold large reserves, and these reserves must as a rule be obtained as equity capital.

I2. The general picture emerging from these considerations consists of two groups. One group seeks to get rid of risk by buying insurance, the other group is willing to accept risk by holding shares in insurance companies. The real problem should then be to find an optimal arrangement for sharing the risks between the members of these two groups.

\section{REFERENCES}

[I] Arrow, K. J., "Optimal Insurance and Generalized Deductibles", Skandinavian Actuarial Journal, 1974, pp. I-42.

[2] Borch, K., "An Attempt to Determine the Optimum Amount of Stop Loss Reinsurance", Transactions of the I6th International Congress of Actuaries, Vol. 2, pp. 579-6ro.

[3] Borch, K., "The Safety Loading of Reinsurance Premiums", Skandinavisk Aktuarietidskrift, I96o, pp. I63-184.

[4] Borch, K., "The Optimal Reinsurance Treaty", The ASTIN Bulletin, Vol. 5, pp. 293-297.

[5] Bühlmand, H., Mathematical Methods in Risk Theory, Springer Verlag, 1970.

[6] KaHN, P. M., "Some Remarks on a Recent Paper by Borch", The ASTIN Bulletin, Vol. I, pp. 265-272.

[7] Ohlin, J., "On a Class of Measures of Dispersion with Application to Optimal Reinsurance", The ASTIN Bulletin, Vol. 5, pp. 249-266.

[8] VAJDA, S., "Minimum Variance Reinsurance", The ASTIN Bulletin, Vol. 2, pp. $257-260$. 